\title{
BMJ Open Introducing physically active lessons in UK secondary schools: feasibility study and pilot cluster-randomised controlled trial
}

\author{
Catherine Gammon, ${ }^{1}$ Katie Morton, ${ }^{1}$ Andrew Atkin, ${ }^{1,2}$ Kirsten Corder, ${ }^{1}$ \\ Andy Daly-Smith, ${ }^{3}$ Thomas Quarmby, ${ }^{3}$ Marc Suhrcke, ${ }^{4,5}$ David Turner, ${ }^{6}$ \\ Esther van Sluijs ${ }^{1}$
}

To cite: Gammon C, Morton K, Atkin A, et al. Introducing physically active lessons in UK secondary schools: feasibility study and pilot cluster-randomised controlled trial. BMJ Open 2019:9:e025080. doi:10.1136/ bmjopen-2018-025080

- Prepublication history and additional material for this paper are available online. To view these files, please visit the journal online (http://dx.doi org/10.1136/bmjopen-2018025080).

Received 28 June 2018 Revised 14 February 2019 Accepted 18 February 2019

Check for updates

(C) Author(s) (or their employer(s)) 2019. Re-use permitted under CC BY-NC. No commercial re-use. See rights and permissions. Published by BMJ.

For numbered affiliations see end of article.

Correspondence to

Dr Esther van Sluijs;

ev234@medschl.cam.ac.uk

\section{ABSTRACT}

Objectives Assess feasibility, acceptability and costs of delivering a physically active lessons (PAL) training programme to secondary school teachers and explore preliminary effectiveness for reducing pupils' sedentary time.

Design and setting Secondary schools in East England; one school participated in a pre-post feasibility study, two in a pilot cluster-randomised controlled trial. In the pilot trial, blinding to group assignment was not possible. Participants Across studies, 321 randomly selected students ( $51 \%$ male; mean age: 12.9 years), 78 teachers (35\% male) and 2 assistant head teachers enrolled; 296 (92\%) students, 69 (88\%) teachers and 2 assistant head teachers completed the studies.

Intervention PAL training was delivered to teachers over two after-school sessions. Teachers were made aware of how to integrate movement into lessons; strategies included students collecting data from the environment for class activities and completing activities posted on classroom walls, instead of sitting at desks.

Primary and secondary outcomes Quantitative and qualitative data were collected to assess feasibility and acceptability of PAL training and delivery. Outcomes were assessed at baseline and $~ 8$ weeks post-training; measures included accelerometer-assessed activity, selfreported well-being and observations of time-on-task. Process evaluation was conducted at follow-up.

Results In the feasibility study, teachers reported good acceptability of PAL training and mixed experiences of delivering PAL. In the pilot study, teachers' acceptability of training was lower and teachers identified aspects of the training in need of review, including the outdoor PAL training and learning challenge of PAL strategies. In both studies, students and assistant head teachers reported good acceptability of the intervention. Preliminary effectiveness for reducing students' sedentary time was not demonstrated in either study.

Conclusions No evidence of preliminary effectiveness on the primary outcome and mixed reports of teachers' acceptability of PAL training suggest the need to review the training. The results do not support continuation of research with the current intervention.

Trial registration number ISRCTN38409550.
Strengths and limitations of this study

- We completed thorough feasibility and pilot testing work to inform the decision of whether to progress with the current intervention and its evaluation.

- We collected quantitative and qualitative data which provided valuable information on contextual influences and allowed us to address research questions more comprehensively.

- We were unable to collect all planned follow-up measures from teachers and students in feasibility study, including teacher follow-up questionnaires and class observations of time-on-task.

- We did not carry out longer-term follow-up measures of teacher acceptability and physically active lesson delivery (ie, beyond $~ 8$ weeks post-training); longer follow-up would have provided an indication of the sustainability of the intervention.

\section{INTRODUCTION}

Globally, most adolescents $(\sim 80 \%)$ do not achieve government-recommended physical activity guidelines ${ }^{1}$ and engage in high levels of sedentary behaviour. ${ }^{2}$ As such, interventions are needed to support youth in achieving a healthy activity profile. Secondary/high schools present an opportunity for the implementation of activity interventions, as during school hours activity is lower and sedentary time is higher than during other segments of an adolescent's week. ${ }^{34}$

The Creating Active School Environments (CASE) project is a 3-year research programme funded by the UK Department of Health Policy Research Programme. CASE aims to identify environmental strategies to help adolescents move more and sit less during school hours. Initial phases of CASE involved a systematic literature review ${ }^{5}$ and secondary data analysis ${ }^{6}$ to identify promising secondary school-based activity 
interventions. Morton et $a l^{7}$ subsequently completed a Delphi study, involving stakeholders in the prioritisation of interventions. Physically active lessons (PAL) were perceived to be the most feasible, acceptable and cost-effective intervention for secondary school settings ${ }^{7}$; these results informed the final, feasibility and pilot-testing phase of CASE.

PAL are a pedagogical approach whereby activity supports the delivery of academic material. ${ }^{8}$ During PAL, movement is integrated into teaching and, as such, PAL are distinct from 'brain/movement breaks', when activity is separate from learning. Evidence from primary schools indicates that PAL can improve physical activity, academic achievement and lesson enjoyment. ${ }^{9-12}$ To our knowledge, only two studies have trialled the use of PAL among adolescents. ${ }^{1314}$ Helgeson ${ }^{13}$ reported no influence of the 'Energizers' PAL programme on reading comprehension scores among junior high school students and did not explore activity levels as a primary outcome. ${ }^{13}$ Cothran et $a l^{14}$ reported on primary and secondary/ high school teachers' experiences of a 1 year movement integration intervention. Compared with primary school teachers, secondary teachers faced different challenges when attempting to integrate activity into lessons, in particular standardised testing pressures and students not staying with one teacher all day (as typically is the case in primary schools) ${ }^{14}$ Cothran et al did not measure student activity behaviours as an intervention outcome. ${ }^{14}$ The positive effects of PAL reported for primary students suggest there is value in exploring if secondary students can experience similar benefits. Given the organisational and environmental differences between primary and secondary schools, it is important to conduct highquality feasibility and pilot testing of secondary school PAL interventions.

A PAL training programme for secondary school teachers was tested in a feasibility study and a cluster-randomised controlled pilot study. The studies aimed to explore the feasibility, acceptability, costs and preliminary effectiveness of a PAL training programme for secondary teachers. Acceptability of study processes was also examined, in anticipation of conducting a subsequent full trial. The feasibility study tested the intervention among maths and English teachers at one school, and the pilot study tested the intervention among all-subject teachers and as part of a controlled trial. This paper presents the feasibility study and pilot study followed by an overall discussion and conclusion.

\section{FEASIBILITY STUDY}

The aim of the feasibility study was to assess (1) the feasibility, acceptability, costs and preliminary effectiveness (for reducing sedentary time and improving well-being and time-on-task among students) of a PAL training programme for secondary school teachers and (2) the feasibility and acceptability of study procedures.
Feasibility study: methods

Recruitment

Potential schools were identified from previous local research and approached with study information $(n=2)$. One mixed-sex, non fee-paying secondary school participated. The head teacher provided written consent for the intervention to be delivered to the teachers, elected for the intervention to be trialled with maths and English teachers, and chose years 7 and 9 to participate in study evaluation measures. The school was told they would be able to keep the PAL training resources.

Parents of all Year 7 and 9 students (11-14 years) received study information and students were invited to participate in evaluation measures. Parents were given 2 weeks to opt out (passive parental consent) via email, freephone or freepost. From the students who had not been opted out, 120 (60 year 7 and 60 year 9 students; $50 \%$ male) were randomly selected for evaluation measures (using class lists and random number generating software). The study's feasibility focus meant that a formal power calculation was not necessary to inform sample size; a sample of 60 participants per year is consistent with samples of similar studies. ${ }^{15}$ Students provided written assent for evaluation measures.

Maths and English teachers $(n=15)$ received study information 2 weeks before the PAL training. The senior leadership team requested that all maths and English teachers attend the training. Teachers could choose to participate in the evaluation measures; those agreeing provided written consent. Over five school days, students received approximately five maths lessons and four English lessons.

\section{Intervention}

The PAL training was developed by a team with teacher training qualifications and experience in indoor (two trainers) and outdoor active learning (one trainer). The training was delivered at the intervention school between March and April, during prescheduled after-school teacher-training time. Table 1 outlines the training programme, and example active lessons are published as online supplementary material. The focus was on supporting teachers to adopt active pedagogical approaches (teaching strategies that incorporate activity), rather than providing new, PAL plans. The training was underpinned by aspects of social cognitive theory and aimed to enhance teachers' self-efficacy in relation to PAL. ${ }^{16}$ As such, it drew from two prominent behaviour change techniques: barrier identification and modelling/demonstrating behaviour. ${ }^{17}$ With the former, teachers were encouraged to identify barriers that might impact their ability to implement PAL and plan ways to overcome these. With the latter, the trainers demonstrated a plethora of PAL teaching strategies that teachers could employ in their lessons. Figure 1 outlines the preliminary logic model of how the teacher-focused intervention could lead to changes in students' activity. Prior to the training, the research team visited the participating school and ascertained the availability of indoor 
Table 1 Outline of the PAL training programme and timeline of evaluation measures

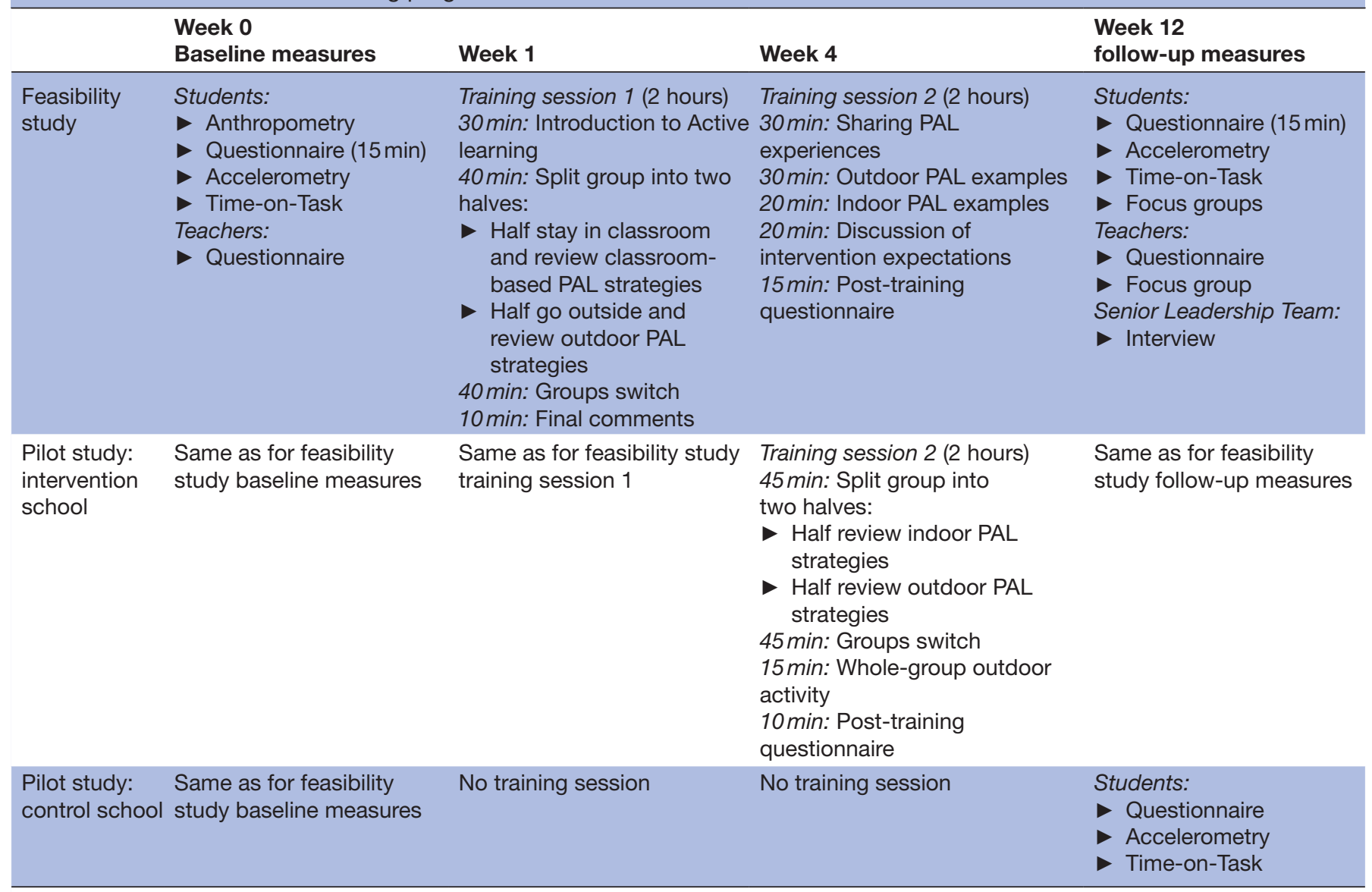

PAL, physically active lessons.

and outdoor spaces and equipment that could be used for PAL. Syllabi for maths and English were requested to allow trainers to prepare relevant examples for the training.

\section{Measurements}

Table 1 outlines the timeline of study measures. Feasibility and acceptability were assessed using questionnaires and focus groups. Three focus groups (with five teachers, eight year 7 and four year 9 students) and an interview with the assistant head teacher were completed using a semistructured interview.

\section{Evaluation of intervention and study}

Feasibility/acceptability of the intervention: Questionnaire items and focus group questions asked about teachers' perceptions of the utility, value and relevance of the

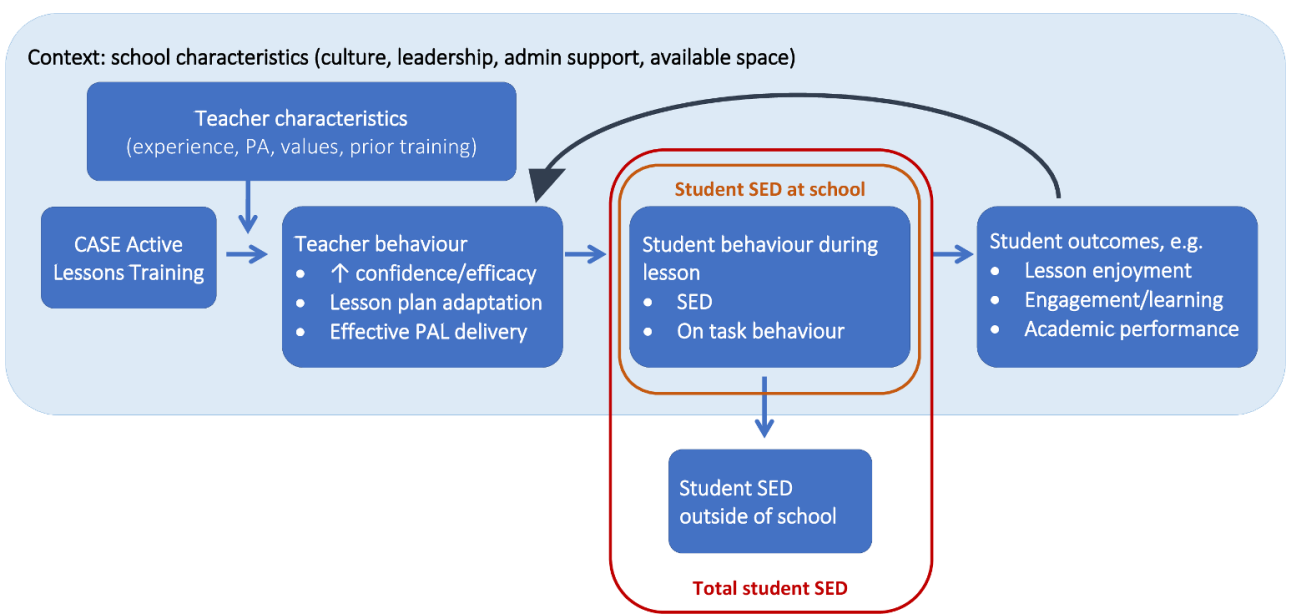

Figure 1 Logic model of how a PAL intervention may result in changes in SED. CASE, Creating Active School Environments; PAL, physically active lessons; SED, student's sedentary activity. 
training (adapted from Gibson et al and Edmundson et $a l^{1819}$ ). Questionnaires asked if teachers would recommend the training to other teachers and provided freetext boxes for teachers to suggest improvements. Training session attendance rates were recorded.

Feasibility/acceptability of PAL delivery: Questionnaire items and focus group questions asked teachers about classroom management during PAL, enjoyment of teaching PAL, time needed to prepare and deliver PAL and barriers to PAL delivery (items from Webster $e t a t^{20}$ ).

Acceptability of PAL participation: Questionnaire items and focus group questions asked students about their experience of PAL participation, enjoyment of PAL, their preference for active versus desk-based lessons and the best and worst things about PAL.

Costs: Teachers and students reported resources purchased to deliver/participate in PAL. The research team recorded time and costs associated with the training team's development and delivery of the intervention.

Study processes: The research team made field notes on study processes that proved to be challenging or ineffective, for example, students struggling to understand a questionnaire item.

\section{Intervention outcomes}

Student anthropometry: Anthropometric measures were completed by trained staff using standard procedures. Height was measured using a stadiometer (Leicester height measure, Chasmors, Leiceter, UK) to the nearest $0.1 \mathrm{~cm}$, and weight was measured to the nearest $0.1 \mathrm{~kg}$ (Tanita, type TBF-300A, Tokyo, Japan). The measurement stations were set up so that results were not visible to anyone except the measurement staff. Height, weight, sex, birth date and measurement date were used to calculate participants' body mass index (BMI; $\left.\mathrm{kg} / \mathrm{m}^{2}\right)$ and BMI percentile.

Activity intensity: Axivity AX3 triaxial wrist-worn accelerometers (non-dominant wrist) were used to measure activity behaviours. These devices have been used among a larger sample of ear 9 participants in the GoActive study ${ }^{21}$ and the UK Biobank Cohort Study. ${ }^{22}$ Wrist-worn monitors are validated for the assessment of energy expenditure in paediatric populations ${ }^{23}$ with higher participant compliance when compared with waist-worn accelerometers. ${ }^{24}$ Participants were given verbal and written instructions on monitor wear, including that the monitor was waterproof and could be worn continuously for the next 7 days (Monday to Monday).

The first day of monitor wear was dropped ${ }^{25}$; included participants provided valid data for $\geq 80 \%$ of school hours for two or more school days, at baseline and follow-up. ${ }^{26-28}$ Acceleration was recorded at $100 \mathrm{~Hz}$ with a dynamic range of $\pm 8 \mathrm{~g}$. Data from the monitors were downloaded in continuous waveform. Euclidean Norm Minus One (ENMO) represents acceleration magnitude at each measurement, accounting for the influence of gravity. ENMO thresholds were used to classify activity intensities: time spent at 0-30 ENMO was classified as sedentary activity (equivalent to $1-1.5$ metabolic equivalents [METs]); 30-210 ENMO as light-intensity activity (1.5-4 METs); 210-500 ENMO as moderate-intensity activity (4-7 METs) and above 500 ENMO as vigorous-intensity activity. ${ }^{29} 30$

Mental health and well-being: Students completed questionnaire measures of positive and negative affect, ${ }^{31}$ academic efficacy, disruptive behaviour, ${ }^{32}$ enjoyment of school classes ${ }^{33}$ and health-related quality of life ${ }^{34-39}$ at baseline and follow-up. All questionnaires are validated for use with adolescents and were analysed according to published instructions. ${ }^{31} 3239$

Time-on-task: Students' time-on-task was assessed during three lessons by one member of the research team using a momentary time-sampling procedure (which incurs less bias than other sampling procedures ${ }^{40}$ ). At the start of each observed class, the teacher asked all students participating in the study to raise their hands. From the students who raised their hands, the researcher identified two boys and two girls (when possible) to observe. The researcher chose students sitting in different areas of the classroom. Each student was observed once per minute, in a consistent order, for the duration of the lesson. Students' behaviour was coded as follows: (1) on-task, (2) off-task-passive, (3) off-task-motor or (4) off-task-noise. ${ }^{42}$ The mean percentage of intervals recorded as 'on-task' for observed students and classes was calculated and used as the outcome measure.

Prior to classroom observations, a validation activity was completed where two researchers discussed definitions and concurrently coded student behaviour using four online videos. Observers' codes matched for $95 \%$ of observation intervals.

\section{Descriptive statistics}

Descriptive statistics of the sample, primary and secondary outcomes and quantitative measures of feasibility and acceptability are summarised. Focus group transcripts were reviewed; recurring comments and themes relevant to the research questions were identified.

\section{Feasibility study: results}

Recruitment and sample characteristics

Student and teacher recruitment and characteristics are summarised in online supplementary tables 1 and 2. Of the 120 students invited to participate in the evaluation measures, 99 were recruited, with 91 (92\%) providing data at baseline and follow-up. Students had a mean age of $13.0( \pm 1.1)$ years, $52 \%$ were male and $27 \%$ were classified as overweight/obese. Teachers were predominantly female $(67 \%)$ and below the age of $45(83 \%)$.

\section{Feasibility and acceptability}

Training session 1 was attended by 14 (out of 15 ) teachers ( 7 maths, 7 English), training session 2 was attended by 12 teachers (7 maths, 5 English), 11 teachers attended both sessions. Teacher feedback demonstrated acceptability of the training, with $100 \%$ recommending the 


\section{Box 1}

'I really enjoyed them (active lessons), they (the students) enjoyed them as well, they seemed to get a lot out of them... it was good fun, it was nothing really any different to what I was normally doing, just with a few added extras' (Maths teacher, female).

'I thought they (the students) would enjoy going outside... I had high hopes for that but it was a Friday afternoon and I don't think they were ready for it... they were causing disruption, they tried to walk off' (English teacher, female).

'we concentrated more because it was more fun than just sitting around' (Year-7, male), and 'when you're sitting down you can get quite bored and get easily distracted whereas if you're moving about you've actually got something to do' (Year-7, female).

training to other teachers (online supplementary table $3)$. Individual and collective efficacy for delivering PAL improved from 2.7 to 3.2 and 2.4 to 3 (out of 4 ), respectively. At follow-up, eight or more teachers had attempted to deliver PAL. Teacher's goals for PAL delivery averaged $2.1(\mathrm{SD}=1.0)$ lessons per week, with an average targeted reduction in sitting time of $15.8(\mathrm{SD}=8.0) \mathrm{min}$. Some teachers reported positive experiences of delivering PAL, while others reported challenges (box 1).

Teacher-reported barriers included disruptive behaviour, lethargy and off-topic chatting, challenges refocusing students after an active portion of class and limited classroom space. Teachers identified facilitators of PAL delivery as theirs and the students' enjoyment of PAL, good weather allowing them to go outside, more classroom space and a more diligent group of students. Teachers reported $\leq 15$ extra minutes were required to plan PAL, and a few extra minutes were needed to prepare students for PAL participation.

Of the students who recalled participating in an active lesson $(47 \%)$, most preferred PAL to desk-based lessons (70\%; 19\% indicated 'no preference') and 93\% wanted teachers to continue delivering them. Students reported enjoying going outside and moving around (30\%), that PAL were less boring/more fun than desk-based lessons
$(26 \%)$ and that they could concentrate better $(14 \%)$. Negative comments about PAL included lethargy (12\%), more disruptive behaviour (9\%) and less work achieved (12\%; box 1).

The assistant head teacher felt the training was well received and was of high-quality professional development. The school's reasons for participating in the project included the potential for improving students' mental health and the motivation to be innovative in the classroom. The assistant head teacher commented that teaching staff had enjoyed taking students outside for lessons and the project had involved a low level of commitment from the school.

\section{Costs}

Training delivery costed $£ 910$, comprising $£ 410$ staff costs and $£ 500$ for training equipment. Participants reported purchasing sticky tape (teacher, $£ 2$ ) and shoes and tights (student, $\sim £ 30$ ).

\section{Study processes}

The majority of study procedures were completed successfully. Challenges encountered included students struggled to complete a blank timetable indicating when their maths and English lessons were, and despite efforts, we were unable to schedule follow-up classroom observations. Teacher baseline questionnaire return was low, and the follow-up focus group was conducted in a 15 min timeslot due to late changes.

\section{Preliminary effectiveness}

Table 2 summarises baseline and follow-up data for all student measures. Sedentary time increased by $8.7 \mathrm{~min}$ and time spent in light-intensity activity decreased by $8.1 \mathrm{~min}$. Minimal changes were observed in the mental health and well-being scores between baseline and follow-up.

\section{Feasibility study: reflections}

The findings suggest it is feasible and acceptable to deliver a PAL training programme to secondary school maths

\begin{tabular}{|c|c|c|c|c|}
\hline & $\mathbf{N}$ & Baseline & Follow-up & Mean difference $(95 \% \mathrm{Cl})$ \\
\hline Sedentary activity (min) & 76 & $237.4(26.4)$ & $246.1(27.6)$ & 8.7 (3.8 to 13.7$)$ \\
\hline Light activity (min) & 76 & $139.8(21.8)$ & $131.7(22.6)$ & $-8.1(-12.4$ to -3.8$)$ \\
\hline Moderate activity (min) & 76 & $10.8(6.0)$ & $10.3(5.8)$ & $-0.6(-1.4$ to 0.3$)$ \\
\hline Vigorous activity (min) & 76 & $2.0(2.0)$ & $1.9(1.8)$ & $-0.1(-0.4$ to 0.3$)$ \\
\hline Time-on-task (\% intervals on-task) & 11 & 66.1 & - & - \\
\hline Academic efficacy (score 1-5) & 85 & $3.51(0.80)$ & $3.63(0.83)$ & - \\
\hline Disruptive behaviour (score 1-5) & 82 & $1.90(0.95)$ & $1.94(0.98)$ & - \\
\hline CHU-9D (score 0.33-1.0) & 89 & $0.86(0.10)$ & $0.84(0.10)$ & - \\
\hline Positive affect (score 1-5) & 81 & $17.35(3.44)$ & $16.16(3.36)$ & - \\
\hline Negative affect (score 1-5) & 84 & $10.55(3.28)$ & $10.71(3.48)$ & - \\
\hline
\end{tabular}

Length of school day $=390 \mathrm{~min}$. 
and English teachers. Importantly, the senior leadership representative was supportive of the training. ${ }^{43}$ Secondary school teachers had mixed reports of delivering PAL, the identified barriers and facilitators were consistent with those previously reported. ${ }^{43}$ It was noted that teacher acceptability of PAL delivery should be explored further in the next phase of intervention evaluation. The positive student response to PAL indicates acceptability and is consistent with results from PAL interventions in primary schools. ${ }^{44}$

We were successful in recruiting and consenting participants, and the majority of evaluation measures were completed without problems. The retention of $>90 \%$ of participants from baseline to follow-up suggests evaluation measures were acceptable. Suggested changes included scheduling all research activities at the start of the project and acquiring student timetables from the school's administration team.

Limitations of this feasibility study include the small sample size and the lack of control group, making it not possible to draw conclusions about the contribution of the intervention to the observed changes. The change in sedentary activity levels is inconsistent with previous research reporting that younger children's sedentary time on weekdays decreases between spring and summer. ${ }^{45}$ Increased negative feelings and lower well-being among students between March and June is consistent with typical changes observed in students' well-being over a school term. ${ }^{46} 47$

\section{PILOT STUDY}

Following successful implementation of the intervention in the feasibility study, we sought to extend our previous work and explore the potential value of conducting a fullscale randomised controlled trial. The aims of the pilot cluster-randomised controlled trial were (1) to assess the feasibility, acceptability, preliminary effectiveness and costs of delivering a PAL intervention at a whole-school level (to all subject teachers) and (2) to test the acceptability of school-level randomisation.

\section{Pilot study: methods}

\section{Recruitment and randomisation}

Schools: We aimed to recruit three schools-two intervention (to test whole-school delivery of the intervention in different settings) and one control (to test the acceptability of school-level randomisation). In June-July 2017, 26 non fee-paying, mixed-gender, secondary schools in the East of England were emailed study information and invited to participate (the school that took part in the feasibility study was not invited to participate in the pilot study). The first three schools to agree were recruited; one school withdrew prior to student recruitment (and randomisation). We were unable to replace the school within an appropriate timeframe. After baseline measures, individuals separate from the research team performed a coin-toss to assign intervention and control schools. The nature of the intervention and goals of the evaluation measures meant it was not possible to blind participants. Due to differences in follow-up measures between control and intervention schools, it was not possible to blind measurement staff at follow-up.

Students: Recruitment proceeded as outlined for the feasibility study. Schools were asked to choose one younger year ( 7 or 8 ) and one older year (9 or 10) group to participate in evaluation measures. This would allow assessment of differential responses to the intervention by age. The intervention school selected Years 7 and 9 and the control school selected Years 8 and 9. Following feasibility study procedures, we randomly selected 130 students $(50 \%$ male, $50 \%$ from each year) from each school for evaluation measures (based on feasibility study retention rates), with the aim of obtaining full data on 100 participants.

Teachers: A teacher information and recruitment meeting was scheduled at both schools, during which a researcher introduced the study and distributed consent forms. Teachers were advised by their senior leadership team that they would be required to attend the PAL training if allocated as the intervention school; all teachers were free to decide on participation in evaluation measures.

\section{Intervention}

Extending the feasibility study, the intervention was delivered to all subject teachers. Training all subject teachers is consistent with the whole-school approach recommended for activity promotion and obesity prevention among youth. ${ }^{48}$ Given the acceptability of the training demonstrated in the feasibility study, the structure and goals of the training for the pilot study were similar. Minimal changes were made to the indoor training component, which focused on generic active learning strategies, applicable to any subject (eg, different workstations around the classroom). In the feasibility study, the outdoor training component provided multiple subject-specific and topic-specific lesson ideas; the inclusion of all subject teachers meant fewer subject-specific examples could be actively worked through during the pilot study training. One additional outdoor lessons trainer was involved to train the larger group of teachers.

\section{Measurements}

Table 1 outlines the timeline of study measures; all data were collected at schools, during school hours. To increase teacher baseline questionnaire return, questionnaires were distributed during the pretraining teacher information meeting, and completed following consent. Data collection followed the same procedures as described for the feasibility study, except for the assessment of PAL dose and time-on-task.

PAL dose: A teacher timetable was created using school-provided student timetables, detailing their Year 7 and 9 lessons. During the student accelerometer assessment at follow-up, teachers were given their personalised 
timetable and asked 'please circle which of the listed Year 7 and/or 9 classes were (or will be) delivered as an active lesson.' Teachers responses were used to calculate PAL dose.

Time-on-task: Four lessons were observed at baseline and follow-up, at both schools. At baseline (prior to delivery of PAL training), the research team observed typical deskbased lessons. At follow-up, the research team asked to observe PAL (instead of desk-based lessons).

\section{Patient and public involvement}

In an earlier phase of CASE, opinions of key stakeholders regarding (1) suitable PA interventions for secondary schools and (2) salient outcomes were explored in a Delphi study ${ }^{7}$. The decision to trial a PAL intervention and inclusion of mental health and time-on-task measures was informed by the Delphi study. While stakeholders were not involved in study design, conduct or recruitment, they reviewed questionnaires and provided feedback on qualitative findings. Student participants received a personal PA report, and participating schools will be provided with a summary of the findings. Assistant head teachers commented on the time commitment of the intervention and teacher participants reported on time spent implementing intervention components.

\section{Descriptive statistics}

Descriptive statistics and focus group analysis proceeded as outlined for the feasibility study.

\section{Pilot study: results}

Figure 2 shows the flow of participants, with further information on student and teacher recruitment and sample characteristics in online supplementary tables 1 and 2. Of the assenting students $(n=222), 92 \%$ provided data at two time points. Half of the students were male and $24 \%$ were classified as overweight/obese. The majority of teachers were female and $>50 \%$ of staff reported delivering at least one PAL a week at baseline. At the intervention school, 30 and 33 teachers attended training session 1 and 2, respectively (29 teachers attended both).

\section{Feasibility and acceptability}

Average scores regarding teachers' acceptability of the training fell below 4 (the 'neutral' value) indicating negative feelings towards the training (online supplementary table 3 ). Teachers reported training activities to be more suited for primary schools and not sufficiently challenging for secondary students. One teacher commented: they were more bonus activities, like extra treat things... you couldn't get much learning done through them' (Science teacher, female). Teachers felt it was assumed they were not delivering PALs prior to the training and this created resistance towards the training effort. Teachers reported that the PAL ideas were not novel and repetitive, the focus on outdoor learning was distracting, and the value of outdoor activities was not clear.

More than half of teachers reported delivering at least one PAL a week at baseline. PAL delivery decreased for
4 teachers $(11 \%)$, was maintained by 6 teachers $(17 \%)$ and increased for 13 teachers $(36 \%)$ (excluding P.E. and drama teachers). At follow-up, teachers indicated they were likely to continue teaching PAL, although they reported concerns about students not learning as much during PAL. Some teachers felt older students could be more lethargic and resistant: 'the younger ones love getting up and interacting with each other. I think the older ones do, it just takes... more effort to get them going' (History teacher, female).

The majority of teachers reported $\leq 15$ min for planning, $\leq 5 \mathrm{~min}$ for classroom preparation and $\leq 5 \mathrm{~min}$ for student preparation. The time needed to deliver an outdoor activity-in particular the transition between indoors and outdoors-was identified as a barrier to implementation. The assistant head teacher also commented about the pitch of the training and poor use of learning time due to transitioning. They felt the indoor component of the training had been more informative and appropriate, and commented staff had used active learning strategies indoors, but not outdoors. Finally, they commented that PAL implementation had declined with time.

Of the students who recalled participating in a PAL $(58 \%),>90 \%$ wanted teachers to continue teaching PAL, with no evidence of differences in intervention acceptability by sex or weight status. Students commented that PAL were fun and helped learning, and they liked moving more: 'I really enjoyed it. It gave me more of an understanding... because when you're just copying off the board some writing I don't always understand it, then when you're moving about it's a lot more clearer' (year 7, female). Students, however, also commented that during PAL some students messed around more and did not focus on work, and work was easier to do when sitting down.

\section{Student PAL dose}

In 1 week, 62/175 lessons (35\%) to year 7 and 9 students were active (31 lessons each). Each teacher delivered an average of 2.2 PALs (range=0-9). Year 7 students received an average of 6.9 PAL (range: $5-10 ; 28 \%$ of 1 week's lessons) and year 9 students, 6.9 PAL (range: $2-13 ; 28 \%)$. This represents the contribution across all subjects.

\section{Costs}

The cost of delivering the training was $£ 901$, comprised of $£ 451$ staff time and $£ 450$ equipment. Session 1 was delivered by three trainers, while session 2 was delivered by four trainers. Four teachers purchased resources to support PAL delivery, including science equipment, textiles equipment, post-it notes and whiteboard pens and printed resources. Four students reported purchasing resources to support PAL participation-three purchased sports shoes ( $£ 30$ per pair) and one a mouth guard $(\sim £ 7)$. 


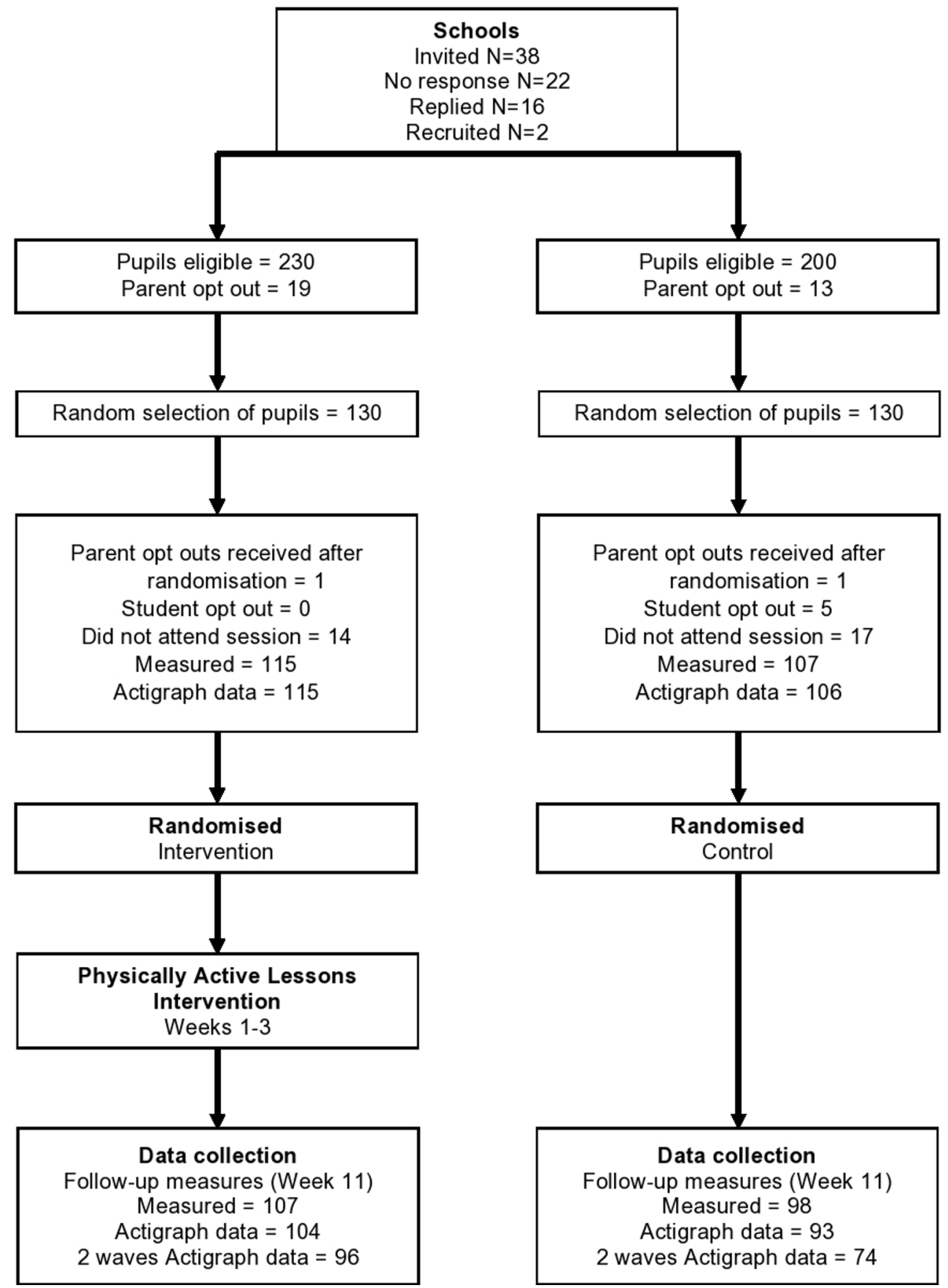

Figure 2 Consolidated Standards of Reporting Trials flowchart of pilot study participant recruitment (schools and students).

\section{Preliminary effectiveness}

Table 3 presents activity intensity during PAL at follow-up and the equivalent lesson at baseline (excluding P.E. and drama lessons). There was no evidence of changes in sedentary activity or time spent in light, moderate and vigorous activity intensities. Table 4 summarises baseline and follow-up values for all outcome measures for intervention and control participants. There was no evidence of preliminary effectiveness on sedentary time or light activity, or on indicators of mental health and well-being (including academic efficacy, positive and negative affect and disruptive behaviour).

\section{Pilot study: reflections}

Extending the work conducted in the feasibility study, this pilot study demonstrates the feasibility of whole-school intervention delivery. However, teachers expressed numerous concerns about the PAL training, including the insufficiently challenging content, lack of understanding of the value/purpose of the outdoor component and potential loss of valuable learning time. These examples are consistent with previous research reporting that time and standardised testing pressures are barriers to PAL implementation, particularly for secondary school teachers. ${ }^{14}$ The feedback suggests a need to review 
Table 3 Activity intensity during 60-min PAL at follow-up and the equivalent lesson at baseline (excluding P.E. and drama); mean (SD)

\begin{tabular}{lllll}
\hline & N & Baseline & Follow-up & $\begin{array}{l}\text { Mean difference } \\
(95 \% \text { Cl) }\end{array}$ \\
\hline $\begin{array}{l}\text { Sedentary } \\
\text { activity (min) }\end{array}$ & 310 & $41.1(8.4)$ & $42.1(8.6)$ & $1.0(-0.1$ to 2.1$)$ \\
$\begin{array}{l}\text { Light } \\
\text { activity (min) }\end{array}$ & 310 & $17.9(7.6)$ & $16.9(7.8)$ & $-1.1(-2.1$ to 0$)$ \\
$\begin{array}{l}\text { Moderate } \\
\text { activity (min) }\end{array}$ & 310 & $0.8(1.0)$ & $0.9(1.0)$ & $0(-0.1$ to 0.2$)$ \\
$\begin{array}{l}\text { Vigorous } \\
\text { activity (min) }\end{array}$ & 310 & $0.2(1.1)$ & $0.2(0.6)$ & $0(-0.1$ to 0.1$)$ \\
\hline
\end{tabular}

PAL, physically active lessons.

the content of the training, particularly the outdoor component.

Teachers comments indicated acceptability of delivering PAL and there was a measurable increase in PAL delivery. Feedback suggests teachers' acceptability may reflect prior knowledge and experience of PAL. In addition, students reported enjoying PAL. Support for the intervention by multiple stakeholders is an important facilitator of successful implementation ${ }^{43}$; as such, the feedback received here is encouraging.

Some students reported purchasing sports shoes and mouthguards for PAL; none of the strategies introduced in the PAL training involved students changing clothing/ shoes or using mouthguards. It is conceivable that when completing the follow-up questionnaire, some students considered P.E. lessons in their appraisal of PAL and reported shoes and mouthguards purchased for this.

We successfully tested study procedures and intervention delivery at a whole-school level, with adequate recruitment and retention rates and continued control school involvement indicating acceptability of randomisation. Efforts made to improve data collection processes from the feasibility study, for example, of student timetables and teacher questionnaires, were successful.

The assessment of PAL dose showed that students received an average of $6-7 \times 60 \mathrm{~min}$ PAL a week, which has the potential to make a valuable contribution to reducing sedentary time among adolescents. Despite a measured increase in PAL delivery, there was no evidence of reduced sedentary time, suggesting a need to review the PAL strategies that were shared with teachers, with a focus on the amount of activity introduced. It is also possible that teachers over-reported PAL delivery out of concern for being judged by the researchers and/or their senior leadership team.

\section{OVERALL DISCUSSION}

In this project, we aimed to assess the feasibility, acceptability, preliminary effectiveness and costs of a teacher-training programme for integrating activity into secondary school lessons. We also sought to understand the feasibility and acceptability of study procedures, including repeated accelerometer wear and school-level randomisation. The intervention was delivered in two schools and quantitative and qualitative data were successfully collected from multiple stakeholders, enabling us to address all research questions. The majority of PAL evaluations have been carried out in primary schools ${ }^{9}$ and as such, this study makes a valuable contribution to the literature.

\section{Feasibility/acceptability of PAL training}

Consistent with previous research, it was feasible to deliver PAL training to secondary school teachers over two, 2-hour, after-school sessions. ${ }^{50}$ Schools scheduled the PAL training during prescheduled after-school teacher-training slots, as such, the intervention did not require teachers to attend any more after-school training than they typically would within a school term. In both studies, a small number of teachers were unable to attend both training sessions which may have influenced intervention outcomes. It is realistic that at any school receiving the intervention, a proportion of staff would be unable to attend both training sessions. As such, the external validity of the findings is supported.

While acceptability of the training was demonstrated in the feasibility study and is reported elsewhere, ${ }^{184450}$ feedback from teachers in the pilot study was less positive. Delivery to teachers of two subjects in the feasibility study meant a smaller training group and a smaller trainer:staff ratio than in the pilot study. This allowed more subject-specific discussion and more time to address teachers' personal questions. Teacher feedback suggests that training acceptability is related to teachers' experience delivering PAL. In the pilot study, teachers delivering PAL more regularly rated the intervention more poorly than less experienced teachers. A PAL intervention targeting teachers not regularly delivering PAL may be more acceptable. The positive responses to the training in the feasibility study (involving teachers reporting low levels of PAL delivery) support this suggestion. Teacher's concerns regarding the lack of learning associated with PAL strategies must be an important consideration in the design of future PAL interventions. Student learning is the core focus of schools, and implementation of PAL is likely to be contingent on teachers perceiving that PAL supports this goal.

\section{Feasibility/acceptability of delivering/participating in PAL}

In the feasibility study, teachers had mixed reviews of delivering PAL, whereas in the pilot study, teachers reported acceptability of delivering PAL. Pilot study teachers were more likely to report regular PAL delivery at baseline than feasibility teachers and to have had previous exposure to PAL during their initial teacher training and/or career. A longer trial period and increased support may have allowed teachers in the feasibility study to become more confident and accrue more positive PAL experiences. 


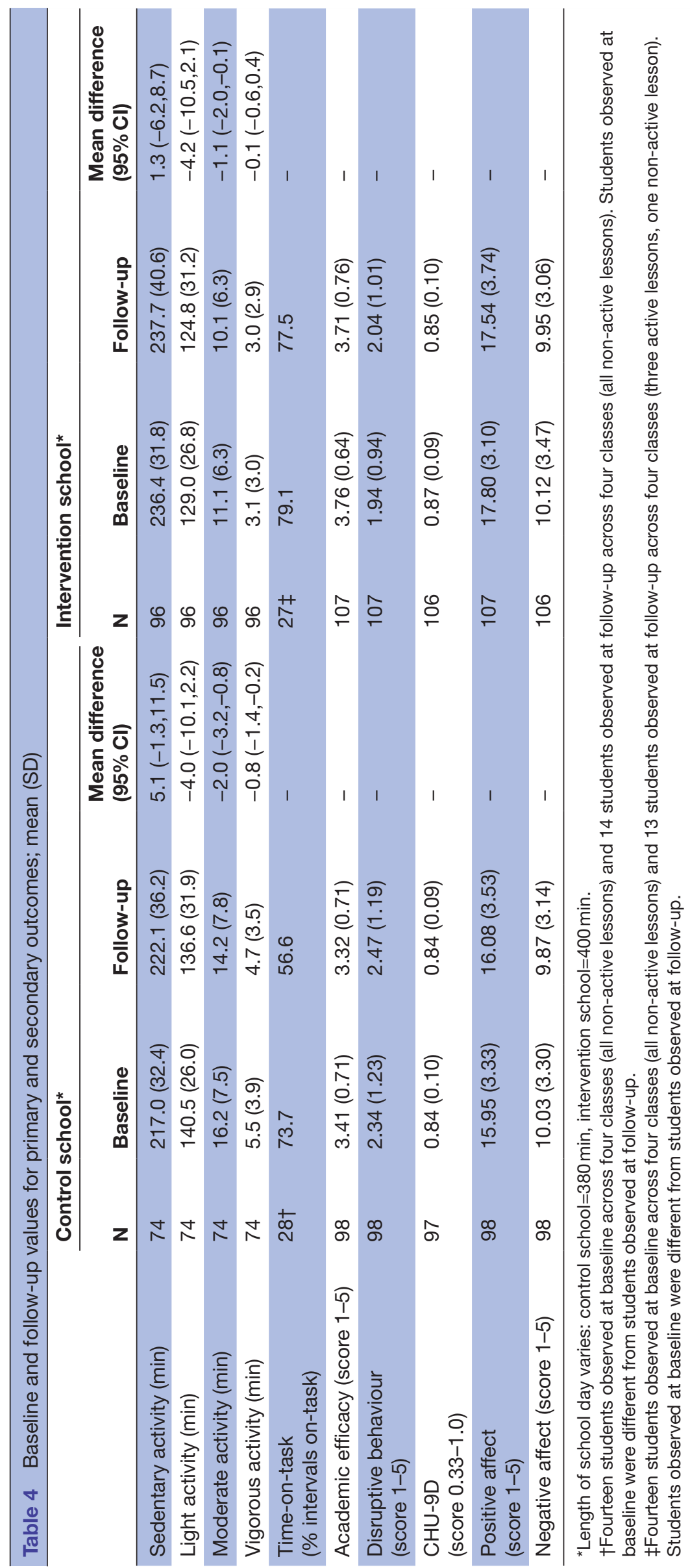


Overall, the data suggest that PAL delivery can be acceptable to secondary school teachers.

While teachers were the direct intervention recipients and their acceptability is crucial for successful implementation, it is important to consider acceptability for other stakeholders, who also influence implementation. Across both studies, students responded positively to PAL, and senior leadership representatives reported satisfaction with the intervention (in the pilot study, satisfaction with the indoor component). Both senior leadership representatives commented that reasons for study participation included the potential positive influence on students' mental health. This observation is consistent with previous findings ${ }^{7}$ and indicates potentially effective strategies for promotion of the intervention to schools.

\section{Preliminary effectiveness}

Despite a measured increase in PAL delivery, no changes in activity were observed. The findings are consistent with a systematic review and meta-analysis of secondary school classroom-based physical activity interventions, which reported no significant influence on activity behaviours. ${ }^{51}$ Although, other PAL feasibility and pilot studies have reported more encouraging changes. ${ }^{42}{ }^{51-53}$ In the feasibility study, early implementation efforts of maths and English teachers may not have been sufficient to translate to changes in activity. It is possible that more or longer training sessions could increase teacher's confidence and competency for delivering PAL, however, initial discussions with the feasibility study school suggested that a 2-hour after-school training session would be acceptable while a 3-hour session would be too long. Across both studies, teachers were advised that any nonseated activity was considered an 'active lesson'-as such, the intervention may be too dilute for measurable impact using wrist-worn accelerometers; classroom observations of PAL (beyond assessing time-on-task) may have aided our interpretation of the findings. Overall, the results suggest the need to review the amount of activity the PAL strategies introduce.

Students received an encouraging dose of PAL (6-7×60 min lessons per week). This dose is consistent with previous studies, for example, $10-30 \mathrm{~min}$ of activity, daily $^{42}{ }^{53-56}$ and $3 \times 60 \mathrm{~min}$ PAL per week. ${ }^{57}$ It is worth noting that teachers in the current pilot study chose how many PAL they delivered, rather than being prescribed a weekly target; as such the dose indicates what is naturally achievable by secondary school teachers. A weekly dose of 6-7 PAL has the potential to substantially reduce adolescents' sedentary time during school hours, providing sufficient activity is introduced as part of the PAL.

\section{Costs}

Training delivery costs (independent of travel and planning time) was estimated around $£ 900(\$ 1187)$ in both studies. Strategies to reduce costs could include reducing the number of staff delivering the sessions or hiring staff with a mixture of training levels, rather than the highly experienced staff in the current studies. Approximately $25 \%$ of the cost was spent on equipment, primarily for outdoor-based subject-specific examples; reviewing the equipment purchases may identify cost saving opportunities. Research reports that small grants $(\sim 2000)$ to schools can lead to increased implementation of practices to promote activity. ${ }^{58}$ Senior leadership teams commented on how thinly English schools budgets are stretched; it was suggested that school funds set aside for (for example) mental health services might represent an avenue of funding for the programme for some schools.

\section{Strengths and limitations}

High-quality formative work for interventions is necessary to ensure appropriate allocation of research efforts and funding, and the publication of feasibility and pilot research is important to support other researchers and interventionists. ${ }^{59}$ Limitations of this work include that samples were predominantly white; consequently, we are unable to explore differential responses to PAL by ethnicity. Moreover, parental opt out consent procedures limited the ability to obtain information on participants' socioeconomic position. The issue of lack of diversity among samples in PAL studies has been previously raised $^{60}$; future research should seek to explore feasibility, acceptability and effectiveness among different racial/ethnic and socioeconomic groups. Estimated training delivery costs are based on wage rates, national insurance and superannuation costs but do not include overhead costs such as costs of employing individuals and providing building space. As such, training delivery costs may be underestimated. In addition, we did not carry out longer-term follow-up assessments, so we do not know if teachers continued to deliver PAL beyond 8 weeks after the training. Finally, we do not believe that lack of blinding of measurement staff has impacted the conclusions drawn from these studies, but acknowledge that a potential fully powered trial would benefit from efforts to blind measurement staff.

\section{CONCLUSION}

We successfully demonstrated the feasibility and acceptability of introducing and evaluating a PAL teacher-training programme in secondary schools. Across feasibility and pilot studies, teachers' acceptability of the intervention and of delivering PAL was demonstrated, although aspects of the training programme, particularly the outdoor component, require review. The intervention was acceptable to students and senior leadership representatives, and the dose of PAL received by students was sufficient to have the potential to make a substantial contribution to reducing adolescents' sedentary time during school hours. However, we did not observe preliminary effectiveness on students' activity behaviours or well-being indicators. Taken together, the findings do not support continuation with the current PAL training programme, though its acceptability does highlight the 
need for further research into how the identified barriers might be overcome.

\section{Author affiliations}

${ }^{1}$ MRC Epidemiology Unit, University of Cambridge, Cambridge, UK

${ }^{2}$ Faculty of Medicine and Health Sciences, University of East Anglia, Norwich, UK

${ }^{3}$ Carnegie School of Sport, Leeds Beckett University, Leeds, UK

${ }^{4}$ Centre for Health Economics, University of York, York, UK

${ }^{5}$ Luxembourg Institute of Socio-Economic Research, (LISER), Esch-sur-Alzette/

Belval, Luxembourg

${ }^{6}$ Norwich Medical School, University of East Anglia, Norwich, UK

Acknowledgements The authors would like to thank the schools, students, teachers, senior leadership representatives and secondary school stakeholders for their participation in, and contributions to, the feasibility and pilot studies. In addition, the authors would like to thank everyone who supported data collection, as well as Colin Farr, Beth Haines and Gwen Brierley for their study co-ordination support and Antonia Smith and Kate Westgate for their assistance in preparing and processing the accelerometer data.

Contributors All authors (CG, KM, AA, KC, AD-S, TQ, MS, DT and ES) contributed to the conceptualisation and design of the work, and reviewed and approved the final manuscript. CG, DT and ES contributed to the acquisition, analysis and interpretation of data. CG drafted the manuscript.

Funding The Creating Active School Environments project is a 3-year programme of research funded by the Department of Health Policy Research Programme (PR-R5-0213-25001). This report is based on independent research commissioned and funded by the NIHR Policy Research Programme (opportunities within the school environment to shift the distribution of activity intensity in adolescents; PR-R5-0213-25001). EvS is supported by the Medical Research Council [MC_UU_12015/7].

Disclaimer The views expressed in the publication are those of the author(s) and not necessarily those of the NHS, the NIHR, the Department of Health, 'arms' length bodies or other government departments.

Competing interests None declared.

Patient consent for publication Not required.

Ethics approval Ethical approval for both studies was granted by the University of Cambridge's School of the Humanities and Social Sciences.

Provenance and peer review Not commissioned; externally peer reviewed.

Data sharing statement The datasets are not available for download. The study's participant information sheets and ethics applications stipulated that the data would not be shared outside of the research team. The data are held at the MRC Epidemiology Unit at the University of Cambridge.

Open access This is an open access article distributed in accordance with the Creative Commons Attribution Non Commercial (CC BY-NC 4.0) license, which permits others to distribute, remix, adapt, build upon this work non-commercially, and license their derivative works on different terms, provided the original work is properly cited, appropriate credit is given, any changes made indicated, and the use is non-commercial. See: http://creativecommons.org/licenses/by-nc/4.0/.

\section{REFERENCES}

1. Hallal PC, Andersen LB, Bull FC, et al. Global physical activity levels: surveillance progress, pitfalls, and prospects. Lancet 2012;380:247-57.

2. Matthews CE, Chen KY, Freedson PS, et al. Amount of time spent in sedentary behaviors in the United States, 2003-2004. Am J Epidemiol 2008;167:875-81.

3. Brooke HL, Atkin AJ, Corder K, et al. Changes in time-segment specific physical activity between ages 10 and 14 years: A longitudinal observational study. J Sci Med Sport 2016;19:29-34.

4. Steele RM, van Sluijs EM, Sharp SJ, et al. An investigation of patterns of children's sedentary and vigorous physical activity throughout the week. Int J Behav Nutr Phys Act 2010;7:88.

5. Morton KL, Atkin AJ, Corder K, et al. The school environment and adolescent physical activity and sedentary behaviour: a mixedstudies systematic review. Obes Rev 2016;17:142-58.

6. Morton KL, Corder K, Suhrcke M, et al. School polices, programmes and facilities, and objectively measured sedentary time, LPA and
MVPA: associations in secondary school and over the transition from primary to secondary school. Int J Behav Nutr Phys Act 2016;13:54.

7. Morton KL, Atkin AJ, Corder K, et al. Engaging stakeholders and target groups in prioritising a public health intervention: the Creating Active School Environments (CASE) online Delphi study. BMJ Open 2017;7:e013340.

8. Bartholomew JB, Jowers EM. Physically active academic lessons in elementary children. Prev Med 2011;52(Suppl 1):S51-S54.

9. Martin R, Murtagh EM. Effect of active lessons on physical activity, academic, and health outcomes: a systematic review. Res $Q$ Exerc Sport 2017;88:149-68.

10. Norris E, Shelton N, Dunsmuir S, et al. Physically active lessons as physical activity and educational interventions: a systematic review of methods and results. Prev Med 2015;72:116-25.

11. Howie EK, Newman-Norlund RD, Pate RR. Smiles count but minutes matter: responses to classroom exercise breaks. Am J Health Behav 2014;38:681-9.

12. Daly-Smith AJ, Zwolinsky S, McKenna J, et al. Systematic review of acute physically active learning and classroom movement breaks on children's physical activity, cognition, academic performance and classroom behaviour: understanding critical design features. BMJ Open Sport Exerc Med 2018;4:e000341.

13. Helgeson J. The impact of physical activity on academics in English classes at the junior high school level. Northcentral University: ProQuest LLC, 2013:188.

14. Cothran DJ, Kulinna PH, Garn AC. Classroom teachers and physical activity integration. Teach Teach Educ 2010;26:1381-8.

15. Mullender-Wijnsma MJ, Hartman E, de Greeff JW, et al. Improving academic performance of school-age children by physical activity in the classroom: 1-year program evaluation. J Sch Health 2015;85:365-71.

16. Bandura A. Social foundations of thought and action: a socialcognitive theory. Englewood Cliffs, NJ: Prentice-Hall, 1986.

17. Abraham $\mathrm{C}$, Michie S. A taxonomy of behavior change techniques used in interventions. Health Psychol 2008;27:379-87.

18. Gibson CA, Smith BK, Dubose KD, et al. Physical activity across the curriculum: year one process evaluation results. Int $J$ Behav Nutr Phys Act 2008;5:36.

19. Edmundson EW, Luton SC, McGraw SA, et al. CATCH: classroom process evaluation in a multicenter trial. Health Educ Q 1994;Suppl 2:S27-S50.

20. Webster CA, Erwin H, Parks M. Relationships Between and Changes in Preservice Classroom Teachers' Efficacy Beliefs, Willingness to Integrate Movement, and Perceived Barriers to Movement Integration. Physical Educator 2013;70:314-35.

21. Brown HE, Whittle F, Jong ST, et al. A cluster randomised controlled trial to evaluate the effectiveness and cost-effectiveness of the GoActive intervention to increase physical activity among adolescents aged 13-14 years. BMJ Open 2017;7:e014419.

22. Sudlow C, Gallacher J, Allen N, et al. UK biobank: an open access resource for identifying the causes of a wide range of complex diseases of middle and old age. PLoS Med 2015;12:e1001779.

23. Phillips LR, Parfitt G, Rowlands AV. Calibration of the GENEA accelerometer for assessment of physical activity intensity in children. J Sci Med Sport 2013;16:124-8.

24. Rosenberger ME, Haskell WL, Albinali F, et al. Estimating activity and sedentary behavior from an accelerometer on the hip or wrist. Med Sci Sports Exerc 2013;45:964-75

25. Dössegger A, Ruch N, Jimmy G, et al. Reactivity to accelerometer measurement of children and adolescents. Med Sci Sports Exerc 2014;46:1140-6.

26. Haapala HL, Hirvensalo MH, Kulmala J, et al. Changes in physical activity and sedentary time in the Finnish Schools on the Move program: a quasi-experimental study. Scand J Med Sci Sports 2017;27:1442-53.

27. Yli-Piipari S, Kulmala JS, Jaakkola T, et al. Objectively measured school day physical activity among elementary students in the United States and Finland. J Phys Act Health 2016;13:440-6.

28. Lau EY, Dowda M, Mclver KL, et al. Changes in physical activity in the school, afterschool, and evening periods during the transition from elementary to middle school. J Sch Health 2017;87:531-7.

29. White T, Westgate K, Wareham NJ, et al. Estimation of physical activity energy expenditure during free-living from wrist accelerometry in UK adults. PLoS One 2016;11:e0167472.

30. Janssen I, Leblanc AG. Systematic review of the health benefits of physical activity and fitness in school-aged children and youth. Int J Behav Nutr Phys Act 2010;7:40.

31. Thompson ER. Development and validation of an internationally reliable short-form of the Positive and Negative Affect Schedule (PANAS). J Cross Cult Psychol 2007;38:227-42. 
32. Midgly C, Maehr ML, Hruda LZ, et al. Manual for the patterns of adaptive learning scales. Michigan, US: University of Michigan, 2000.

33. Jones RD. Student engagement. Teacher handbook. New York: Center for Leadership in Education, 2009.

34. Furber G, Segal L. The validity of the Child Health Utility instrument (CHU9D) as a routine outcome measure for use in child and adolescent mental health services. Health Qual Life Outcomes 2015;13:22.

35. Stevens K. Developing a descriptive system for a new preferencebased measure of health-related quality of life for children. Qual Life Res 2009;18:1105-13.

36. Stevens $\mathrm{K}$. Assessing the performance of a new generic measure of health-related quality of life for children and refining it for use in health state valuation. Appl Health Econ Health Policy 2011:9:157-69.

37. Stevens K. The Child Health Utility 9D (CHU9D) - A New Paediatric Preference Based Measure of Health Related Quality of Life, in PRO Newsletter, 2010.

38. Stevens KJ. Working with children to develop dimensions for a preference-based, generic, pediatric, health-related quality-of-life measure. Qual Health Res 2010;20:340-51.

39. Stevens K. The development of a preference based paediatric health related quality of life measure for use in economic evaluation. Sheffield: The University of Sheffield, 2008.

40. Hintze JM, V.R. J, Shapiro ES. Best practices in the systematic direct observation of student behaviour. 2002;4:993-1006.

41. Johnson AH, Chafouleas SM, Briesch AM. Dependability of data derived from time sampling methods with multiple observation targets. Sch Psychol Q 2017;32:22-34.

42. Mahar MT, Murphy SK, Rowe DA, et al. Effects of a classroom-based program on physical activity and on-task behavior. Med Sci Sports Exerc 2006;38:2086-94.

43. Nathan N, Elton B, Babic M, et al. Barriers and facilitators to the implementation of physical activity policies in schools: A systematic review. Prev Med 2018;107:45-53.

44. Dyrstad SM, Kvalø SE, Alstveit M, et al. Physically active academic lessons: acceptance, barriers and facilitators for implementation. BMC Public Health 2018;18:322.

45. Atkin AJ, Sharp SJ, Harrison F, et al. Seasonal variation in children's physical activity and sedentary time. Med Sci Sports Exerc 2016;48:449-56.

46. Verma S, Allen NB, Trinder J, et al. Highs and lows: Naturalistic changes in mood and everyday hassles over school and vacation periods in adolescents. $J$ Adolesc 2017;61:17-21.

47. Eminson K, Canaway A, Adab P, et al. How does age affect the relationship between weight and health utility during the middle years of childhood? Qual Life Res 2018;27:1455-62.
48. Lee A. Health-promoting schools: evidence for a holistic approach to promoting health and improving health literacy. Appl Health Econ Health Policy 2009;7:11-17.

49. Committee on Physical Activity Physical Education in the School. In: Kohl HW, Cook HD, eds. Educating the student body: taking physical activity and physical education to school. Washington (DC): National Academies Press (US), 2013.

50. Hankonen N, Heino MT, Hynynen ST, et al. Randomised controlled feasibility study of a school-based multi-level intervention to increase physical activity and decrease sedentary behaviour among vocational school students. Int J Behav Nutr Phys Act 2017;14:37.

51. McMichan L, Gibson AM, Rowe DA. Classroom-based physical activity and sedentary behavior interventions in adolescents: a systematic review and meta-analysis. J Phys Act Health 2018;15:383-93.

52. Oliver M, Schofield G, McEvoy E. An integrated curriculum approach to increasing habitual physical activity in children: a feasibility study. J Sch Health 2006;76:74-9.

53. Erwin HE, Abel MG, Beighle A, et al. Promoting children's health through physically active math classes: a pilot study. Health Promot Pract 2011;12:244-51.

54. Reznik M, Wylie-Rosett J, Kim M, et al. A classroom-based physical activity intervention for urban kindergarten and first-grade students: a feasibility study. Child Obes 2015;11:314-24.

55. Li YP, Hu XQ, Schouten EG, et al. Report on childhood obesity in China (8): effects and sustainability of physical activity intervention on body composition of Chinese youth. Biomed Environ Sci 2010;23:180-7.

56. Donnelly JE, Greene JL, Gibson CA, et al. Physical Activity Across the Curriculum (PAAC): a randomized controlled trial to promote physical activity and diminish overweight and obesity in elementary school children. Prev Med 2009;49:336-41.

57. Riley N, Lubans DR, Morgan PJ, et al. Outcomes and process evaluation of a programme integrating physical activity into the primary school mathematics curriculum: The EASY Minds pilot randomised controlled trial. J Sci Med Sport 2015;18:656-61.

58. Miller GF, Sliwa S, Michael S, et al. Evaluation of Let's Move! active schools activation grants. Prev Med 2018;108:36-40.

59. Jago R, Sebire SJ. Publishing pilot and feasibility evaluations of behavioural interventions: implications for preventive medicine. Prev Med 2012;55:548-9.

60. Benjamin Neelon SE, Hesketh KR, van Sluijs EM. Will physically active lessons improve academic achievement for all or widen the achievement gap? Pediatrics 2016;137:e20154137. 